\title{
A Prototype Web-Based User Interface for Sustainability Modeling and Optimization
}

\author{
Guodong Shao \\ David Westbrook \\ Alexander Brodsky
}

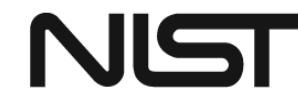


NISTIR 7850

\title{
A Prototype Web-Based User Interface for Sustainability Modeling and Optimization
}

\author{
Guodong Shao \\ Systems Integration Division \\ Engineering Laboratory \\ David Westbrook \\ Computer Science Department \\ University of Maryland \\ Alexander Brodsky \\ Computer Science Department \\ George Mason University
}

March 2012

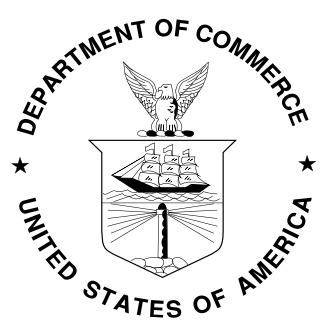

U.S. Department of Commerce John E. Bryson, Secretary

National Institute of Standards and Technology Patrick D. Gallagher, Under Secretary of Commerce for Standards and Technology and Director 


\title{
A Prototype Web-Based User Interface for Sustainability Modeling and Optimization
}

\author{
Guodong Shao \\ System Integration Division \\ Engineering Laboratory \\ National Institute of Standards \\ and Technology \\ Gaithersburg, MD 20899, U.S.A.
}

\author{
David Westbrook \\ Computer Science Department \\ University of Maryland \\ College Park, MD 20742, \\ U.S.A.
}

\author{
Alexander Brodsky \\ Computer Science \\ Department \\ George Mason University \\ Fairfax, VA 22030, U.S.A.
}

\begin{abstract}
A growing number of manufacturing industries are initiating efforts to address sustainability issues. Energy efficient manufacturing and low carbon manufacturing are gaining particular attention. Finding the optimal solution of operational strategy and investment planning by analyzing different options is important to decision makers as it allows them to make decisions to avoid the unnecessary high cost of energy and lower the associated carbon emissions. A decision guidance database system introduced in this paper enables the sustainability modeling and optimization for manufacturing processes. A graphical user interface of the database system will conveniently provide decision makers with analysis results and appropriate decision recommendations. This paper discusses the case studies developed previously using the decision guidance database tool and the development of a prototype web-based user interface for these case studies. This prototype provides foundation for future research on sustainability modeling and optimization and the tool can be easily enhanced to become a publicly available tool and used for more complex manufacturing processes and systems.
\end{abstract}

Keywords: sustainable manufacturing; sustainable machining; energy management; decision guidance query language; optimization; user interface.

\section{Introduction}

Sustainable manufacturing has recently gained an increasing global interest (Seliger et al. 2011). According to the Department of Commerce, sustainable manufacturing is "the creation of manufactured products that use processes that minimize negative environmental impacts, conserve energy and natural resources, are safe for employees, communities, and consumers and are economically sound" (DOC 2010). The manufacturing sector accounts for about one third of all energy consumed in the United States (NAM 2010). Therefore, the U.S. manufacturing companies are starting to realize the importance of energy-efficient manufacturing. According to the U.S. Energy Information Administration (EIA), the cost of energy will substantially increase in the next two decades. Therefore, manufacturers who do not have much leeway when it comes to raising prices on their goods, will have to learn to run factories on less energy or risk financial strain (Rockwell 2010). The manufacturing industry has made progress with sustainability projects and energy management (Fujitsu. 2011, GM 2010, Mort 2010, SAIC 2011). However, most of them are stand-alone projects. The solutions are provided on a problem by problem basis, without a systematically structured and generalized reusable approach. Many of the complex interactions were not taken into account and could not be handled. Only those manufacturers that plan to manage energy efficiency and emissions systematically, dynamically, consistently, quantitatively, and optimally will have a competitive advantage going 
forward. They need methodologies and decision tools, which provide measurement science-based assessment, evaluation, and decision guidance, to achieve this higher-level energy management (Choi et al. 2003, USCEEM 2011).

Decision optimization is an effective tool to make the best decision out of a multitude of possible alternatives by using rigorous mathematical techniques. A typical optimization model used in operations research (OR) specifies (1) decision variables, (2) constraints that have to be satisfied, and (3) an objective function to be optimized. However, modeling of a manufacturing process using OR tools such as Mathematical Programming (MP) and Constraint Programming (CP) presents a considerable challenge due to the complexity of both the problem and the tool. The MP modeling abstraction (e.g., A Modeling Language for Mathematical Programming (AMPL) (AMPL 2011, Fourer et al. 2002) or the General Algebraic Modeling System (GAMS) (GAMS 2012)) typically requires OR expertise and mathematical training (Brodsky et al. 2011).

Brodsky and Wang (2008) proposed a Decision Guidance Management System (DGMS) that supports what-if analysis, monitoring and control, statistical learning, and decision optimization using Decision Guidance Query Language (DGQL), which is an extension of the relational model with probability distributions over a set of attributes as random variables. The DGQL combines the database application modeling with optimization algorithms. The structured query language (SQL) is used to create abstract models and DGQL commands are used to formulate optimization problems as an MP formulation. The optimization problem is submitted to an external mathematical solver such as IBM ILOG CPLEX (CPLEX 2010), which takes the optimization objective, as well as applicable equations, inequalities, and algorithms to derive an optimization solution. The optimal solutions will be sent back to the database to replace the decision variables. Taking a sustainable manufacturing application as an example, DGQL views can utilize existing factory data such as energy consumption, production, technology, budget, and cost to formulate and solve an optimization problem, e.g., optimal energy usage to minimize the total cost. It is easy and intuitive for database application developers.

The National Institute of Standards and Technology (NIST) Sustainable Manufacturing (SM) program is based on developing and deploying measurement science to achieve sustainability across manufacturing processes. This enables manufacturing resource efficiency and production network resiliency. The program will provide industry with the needed tools and infrastructure to enable and accelerate the development of production models capable of evaluating sustainability performance at the unit, plant floor, and supplier network levels. Sustainability Modeling and Optimization (SMO) is a project within the NIST SM program. The objective of the project is to develop a measurementscience-based integration framework for sustainable manufacturing to support (1) common concepts and models that facilitate integration of engineering information systems, (2) generic optimization approaches to aid performance assessment and decision making, and (3) common verification and validation methods to ensure credible modeling and analysis.

The DGQL decision guidance tool (Brodsky and Wang 2008, Brodsky et al. 2011) is one of the candidate tools for the SMO project to explore, implement, test, verify, and validate the generic optimization approaches. Two sustainability modeling and optimization case studies - Energy Efficiency Manufacturing and Sustainable Machining have been implemented using the DGQL tool (Shao et al. 2011a, Shao et al. 2011b). This paper discusses a prototype web-based user interface developed based on these case studies. Although not yet publicly available, we anticipate that the webbased user interface will provide users easy access to the optimization databases.

The paper is subdivided into five main sections. The next section introduces the proposed decision guidance framework that includes the system users and user interface needs. Section 3 reviews the two sustainability modeling and optimization case studies. Section 4 introduces the design and development of the prototype web-based user interface for the two case studies. Finally, in Section 5, a summary is provided. 


\section{Decision Guidance Framework}

Achieving sustainable manufacturing involves predicting the behavior of a complex system and making decisions to reduce energy consumption and carbon emissions, and save operational costs, while maintaining desirable production and people-comfort levels. Predictions and decisions will be made in the presence of large amounts of dynamically collected data and learned uncertainty models. Figure 1 shows the DGMS application implementation architecture that provides measurement-science based optimal decision making for sustainable manufacturing. The measurement science applied includes sustainability indicators and metrics, measurement methods for energy, emissions, material, sustainable manufacturing data models, and assessment methods. The different layers of the decision guidance framework are addressed in the following sub-sections.

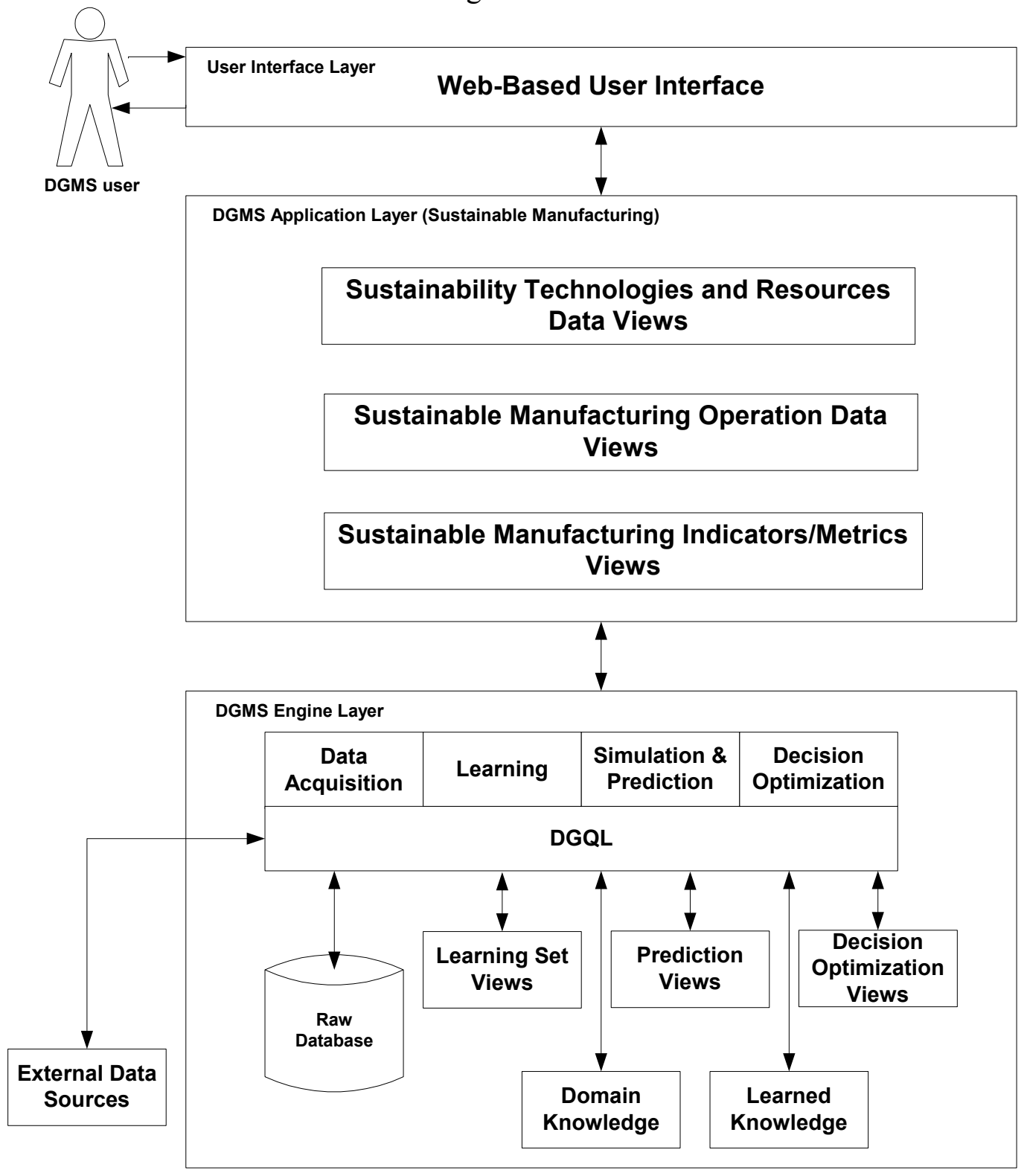

Figure 1. Framework of decision guidance for sustainable manufacturing. 


\subsection{DGMS engine layer}

The DGMS engine layer depicted in Figure 1 is a productivity platform for iterative development of decision-guidance systems. DGQL supports the integration of (1) querying the data collection and construction of learning sets; (2) learning from the learning sets, using parameterized transformers and optionally defining an estimation utility, such as sum of squares of errors, to be minimized; (3) probabilistic prediction and simulation using expressions that involve random variables, such as expectation, variance, and probability of a logical formula; and (4) stochastic or deterministic optimization, where the search space is defined as a set of feasible non-deterministic query evaluations. The domain knowledge for all these tasks is expressed in a parameterized database query language, so that the development of models would be as simple as the development of a database (DB) reporting application. The DGMS combines the extensibility of database application modeling with the benefits of optimization algorithms based on MP and CP. DGMS functions can be automatically derived by the compiler from abstract model views, which are written using SQL. These abstract models may describe sustainable manufacturing application components and factors such as machining operations, equipments, tools, products, energy efficiency, emissions control, and local power generations. The SQL models can be annotated by indicating that some of the table columns are unknown and the value it computes is to be used as an optimization objective. Given this information, DGMS will automatically generate, at run time, a formal MP problem and deploy a mix of algorithms best suited for the problem at hand; e.g., Mixed Integer Linear Programming (MILP) using IBM ILOG CPLEX solver. Therefore, when a new factor for manufacturing applications is introduced, the only requirement to form its optimization problem is to add a DGQL for this component. All systems static and dynamic data will be normalized and stored in a Relational Database Management System (RDBMS).

\subsection{DGMS application layer}

To achieve sustainable manufacturing, industries are seeking not only the long-term strategic directions but also the improvement of operational performance towards sustainability. DGMS/DGQL will help the users formulate the optimization problem that utilizes existing factory data such as energy consumption, production, technology, and cost. In this layer, DGQL views need to be developed and stored. These views should be used as modular building blocks and templates to solve other manufacturing problems. The templates library provides reusable models and algorithms for a family of manufacturing processes; each template can be reused with minor adjustment for different cases within the family. A new type of applications can be added to the templates' library. Moreover, the existing type of applications within the library can be executed with new data so that different manufacturers that have the same problems could use the template by inputting their data to seek company-specific optimal decision guidance.

As shown in Figure 1, the DGMS application layer includes three categories of views. The first two sets of views deal with the definition of the required data for DGQL. The last view provides computations of the indicators and metrics. The views are described in the following subsections.

\subsubsection{Sustainability technologies and resources data views}

To make optimal decisions based on given requirements and budget constraints for new technologies and systems, the templates for storing the sustainability technology and resources' data need to be designed and ready to be populated.

The sustainability technologies and resources data views include data schemas for technologies and resources such as solar panels; standby generators; Heating, Ventilation, and Air Conditioning (HVAC) system; Energy Management System (EMS); heat recovery system; machine center; cutting 
tool; material; and coolant. Life Cycle Assessment (LCA) reference data also belongs to this category (EPA 2010). The data need to be formatted and stored in DB tables. For example, a generator data schema is as follows:

Generator (g_id, g_name, g_price, g_annual-maintenance, g_fuel-cost)

The schema shows the identifiers, names, prices, annual maintenance fees, and fuel cost of the generators in the database. The database schema can be populated using data from product specification and engineering information systems.

\subsubsection{Sustainable manufacturing operation data views}

Most manufacturing facilities need to better track and improve their performance on energy, material, and water usage, and control greenhouse gas emissions and waste. While sustainability technologies and resources data view cover the product data, the sustainable manufacturing operation view deals with the process data, machine setting data, and condition and constraint data such as cutting speed, cutting time, cutting tool life, amount of coolant needed, energy consumed, and carbon emission amount. For example, a machine spindle speed table is as follows:

SpindleSpeed (mID, tID, pID, sID, sSpeed) schema gives the spindle speed (sSpeed) on a particular stock (sID) for the product (pID) being produced using a particular tool (tID) on a particular machine (mID).

\subsubsection{Sustainable manufacturing indicators and metrics' views}

The product and process data views provide the required data. However, to perform decision optimization, the analyst also needs to determine the indicators for sustainable manufacturing and their metrics. Algorithms to calculate these metrics need to be in place. The sustainable manufacturing indicators and metrics' views provide computation model templates and representations for formulas and algorithms. For example, it may include total energy produced by a solar panel, total natural gas consumed by a generator, emission levels, energy cost, payback period, Return on Investment (ROI), and waste generated. The NIST metrics for products and processes sustainability performance (Feng et al. 2010) can be referenced when developing this view. An example of this view is as follows:

CREATE VIEW Metal_Chips_Emission

SELECT p.pID, (s.Volume - p.Volume) * m.mDensity *m.WDe AS MCE

FROM Product $\mathrm{p}$, Stock s, Material m

WHERE p.maID $=$ m.maID and s.maID $=$ m.maID

Where WDe is a factor from an LCA database for material disposal.

\subsection{User interface layer}

User interface enables the communication between the system and its users, it provides users with particular functionalities to access the information within the DGMS application layer. This information includes input data, computations, optimizations, and actionable recommendations. Figure 2 shows the use case diagram for decision guidance of sustainable manufacturing. There are four types of potential users for the system:

- Vendor: The vendor is a supplier of products and/or technologies, which are used by manufacturers. The vendor publishes and updates its products data in the system through a web-based user interface, so that customers can query most up-to-date product information. Product specification data includes product name, type, capacity, size, and price.

- Customer: The customer is a potential buyer of the technology or products. S/he may query existing 
products information such as product name, type, capacity, size, and price through a web-based user interface.

- Decision maker: The decision maker is the primary user of the system. By submitting a decision object query with input constraints and conditions, s/he could get an actionable recommendation for a specific problem.

- System developer: The system developer serves as system administrator who can update system data, create new applications, modify/improve system design, and maintain/debug the system.

A user interface can be developed using web-services such as Java Database Connectivity Application Programming Interface (JDBC API) or any specific application.

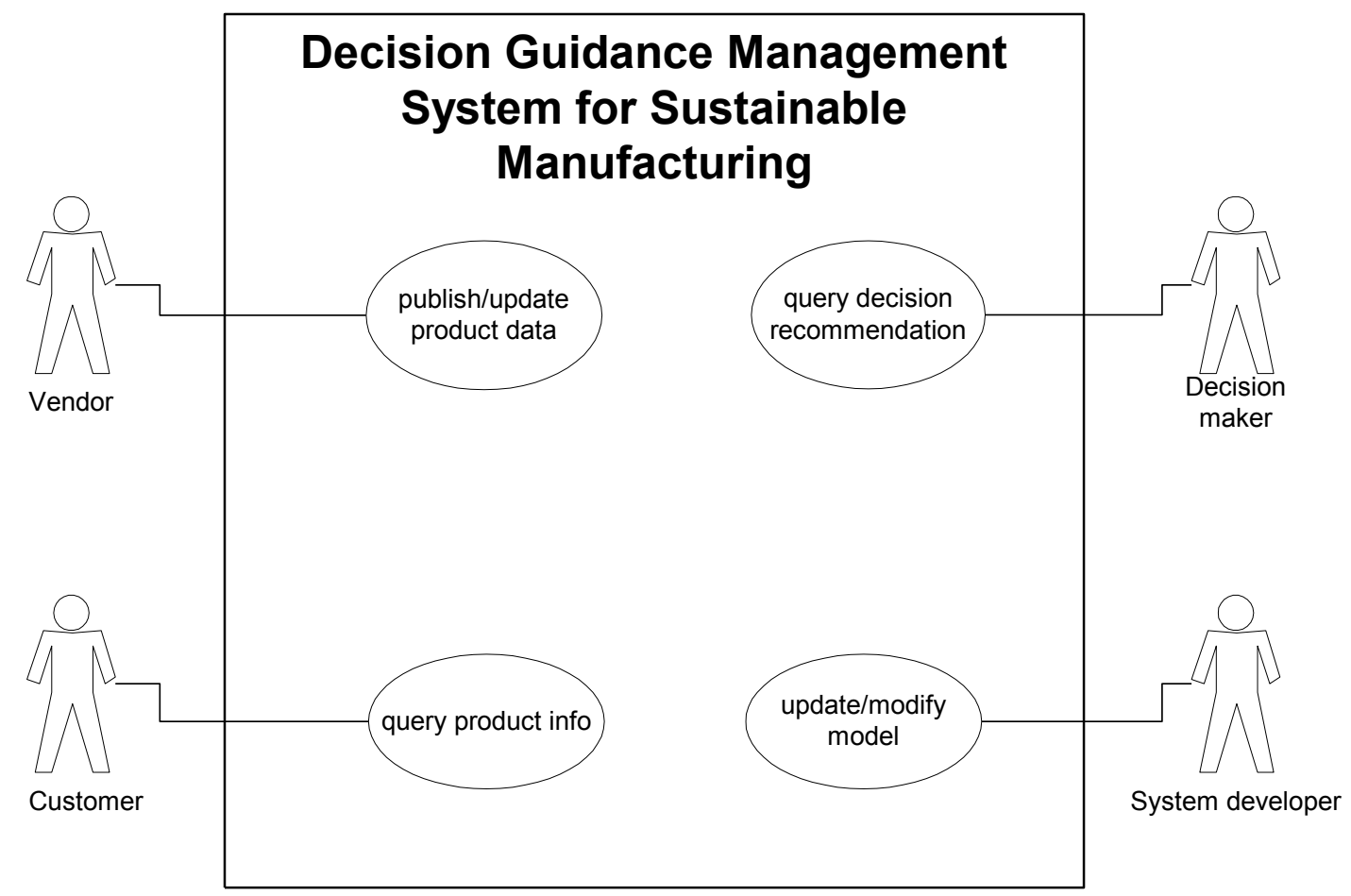

Figure 2. Use cases of the decision guidance management system for sustainable manufacturing.

\section{Two Case Studies for Sustainable Manufacturing Modeling and Optimization}

Case studies, using DGQL, can be conducted to analyze, evaluate, and improve the sustainability performance of manufacturing processes, systems, and organizations. Such studies are designed to solve specific optimization problems and to answer specific objective questions.

In general, the goal of DGQL modeling is to provide a quantitative analysis for manufacturing processes, workflow, schedules, and to determine material, labor, equipment, tooling, inventory, material handling, and maintenance requirements in order to manage energy, emission, and waste. The activities for performing such a case study include 1) identifying a manufacturing problem for study, 2) collecting domain knowledge for that problem, such as identifying the indicators and their metrics, 3) developing a formal data model for the problem, collecting and processing available data, calibrating the model for unknown parameters, 4) determining the decision objectives and constraints, and 5) formulating and solving the optimization problem using DGQL. Two independent case studies from different categories are presented briefly in the following subsections. The DGQL models for these case studies are stored in the model library for future reuse. 


\subsection{Investment/planning for Energy Efficient Manufacturing}

Manufacturers have been putting higher priority on meeting production requirements than on energy management. With the increasing energy price, government regulation, and environmental concerns, factory decision makers have to make decisions based on achieving energy-efficient manufacturing.

The objective of this case study is to find the best energy usage patterns. Because of the complexity of systems, processes, and data, the decision making for investment and strategic planning is not a straightforward process. The inputs to these models may include data associated with budget, regulatory policies, the contract and incentives, and taxes.

A large factor of electricity cost in manufacturing industries is the peak electric demand. Manufacturers can schedule their machines and equipment to run during periods of lower demand, but sometimes this is not possible. One of the more reasonable approaches is to use local generators during the periods of peak demand, but determining the appropriate configuration of local generators is also complicated. The components are interdependent and the interactions among them are complex, all the factors such as brand, type, size, capacity, and efficiency have to be taken into account. Shao et al. (2011a) has modeled energy demand control using DGQL for a manufacturing facility. The model is used to determine optimal investment of a combination of standby generators and/or renewable energy sources to improve energy efficiency, lower energy cost, and reduce the carbon footprint. Figure 3 illustrates the flow, inputs, and outputs of the model.

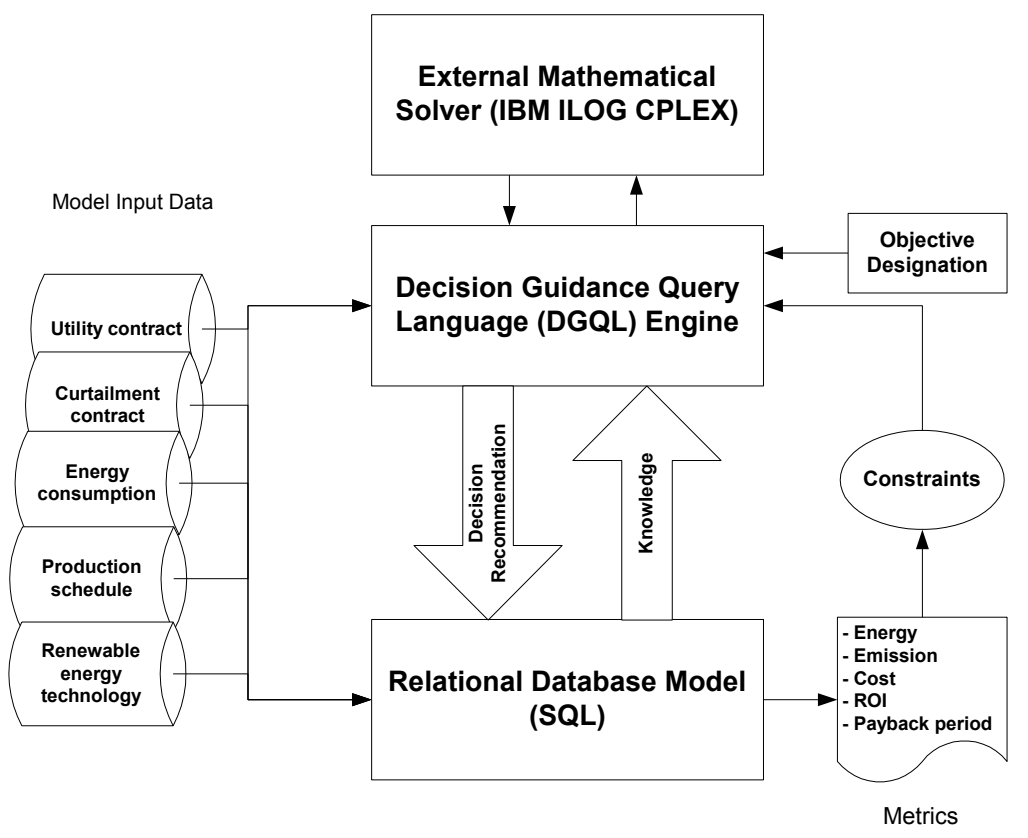

Figure 3. Energy-efficient manufacturing DGQL modeling diagram.

The following activities were involved.

1. Developed a methodology and metrics for assessing the energy-efficient manufacturing planning and investment.

2. Identified data including energy consumption of both production loads and facility building services, and renewable energy technology data.

3. Collected data from sources such as utility contract, curtailment contract, production database, EMS, and vendor' product specifications.

4. Developed the data schema and stored the data into a RDBMS, which is the format that is ready for 
DGQL modeling.

5. Developed DGQL views to calculate energy consumption, emissions, cost, and ROI for different scenarios. Constraints included the budget available, energy required, and limiting carbon emission.

6. Formulated an optimization problem and submitted it to the external solver.

7. Retrieved the optimal solution from the optimized database.

8. Made recommendations of purchase plans for local generators, and renewable energy sources such as solar panels.

\subsection{Operation of low carbon manufacturing}

To achieve sustainable and low carbon manufacturing, efforts to analyze and improve the energy usage and carbon emissions at the unit manufacturing process level are necessary. Depending on the objective, different approaches can be implemented at the workstation and machine level. A case study on this aspect assists decision making on machining purchases by determining optimal cutting conditions (spindle speed and cutting speed) for the most energy-efficient and environmentally-friendly machining. The spindle speed of conventional milling is relatively slow and it results in a longer machining time, causing an unnecessary excess of carbon dioxide emission (Desmira et al. 2009). The energy usage can be lowered if the spindle speed is increased, as this reduces the overall machining time. Finding the optimal speed to run a machine often comes down to solving the behavior problems of a complex system. As the spindle speed is increased, other parts on the machine and tooling take durability losses and their costs have to be taken into account. Eventually the disposal processes of tooling and other substances also cause an effect on the environment.

Shao et al. (2011b) has performed a case study of low carbon machining using DGQL. Figure 4 illustrates the inputs and outputs for the machining model. The following activities were involved:

1. Developed a methodology and metrics for assessing the sustainability performance of a machining process. All factors including electricity consumption, tool usage, lubricant, coolant, and chips were each converted to equivalent $\mathrm{CO}_{2}$ emission. The optimal cutting conditions were obtained for lowest total system emission.

2. Designed and deployed a data collection methodology. Data for resources' components such as machine, tool, coolant, lubricant, and material were extracted from the LCI database, production database, and machine tool specifications.

3. Developed DGQL tables and views to formulate the optimization problem and submitted it to an external solver.

4. Recommended a high-speed milling machine tool purchase based on the optimal cutting speed that led to a minimum total $\mathrm{CO}_{2}$ emission. In this case, the spindle speed is $6400 \mathrm{rpm}$, cutting speed is $200.96 \mathrm{~m} / \mathrm{min}$, and feed rate is $1280 \mathrm{~mm} / \mathrm{min}$. 


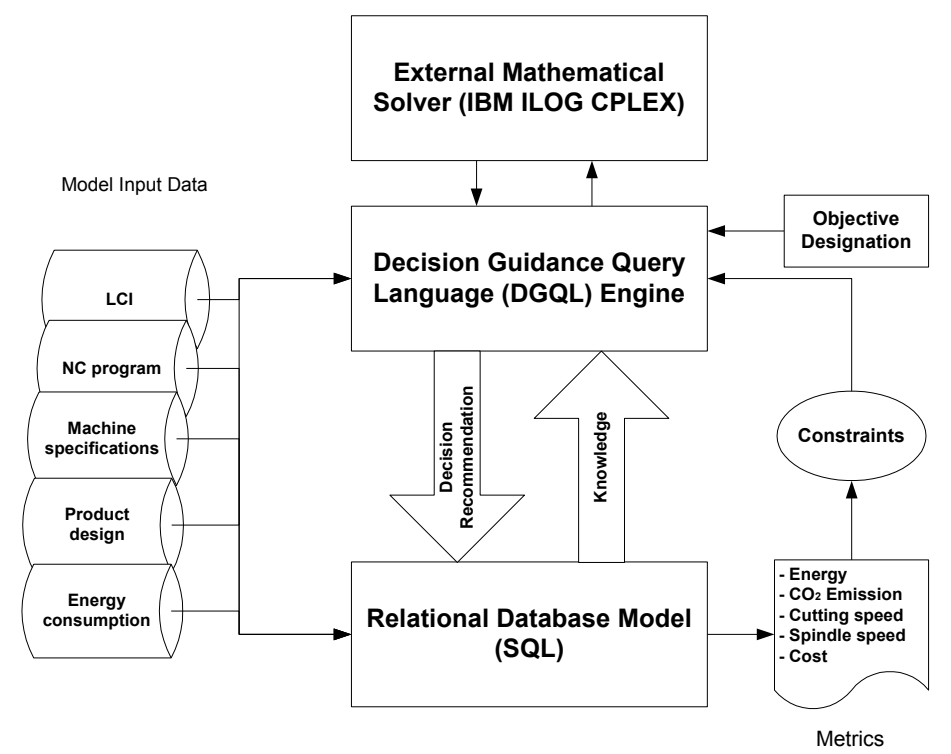

Figure 4. Sustainable machining DGQL modelling diagram.

\section{Web-Based User Interface}

A prototype web-based user interface was developed for the case studies discussed in the previous section. It will be accessed using any web browser once it is publicly available to:

- Provide users easy access to an optimized database

- Update data records in the database

- Display inputs, computations, optimizations, and actionable recommendations

In addition, it will provide password protected user-specific functionalities.

Figure 5 illustrates the prototype web-based graphical user interface (GUI) component diagram. The following applications and programming languages are used: Tomcat, Hypertext Markup Language (HTML), Java Database Connectivity (JDBC), and PostgreSQL.

- PostgreSQL is an open source object-relational database system. It provides a platform upon which to develop in-house, web, or commercial software products that require a capable RDBMS (PostgreSQL 2010). The DGQL case study models described in the previous section reside within the PostgreSQL database.

- Tomcat is a web server application that provides the web-based user interface with a unique Internet Protocol (IP) address, which can be accessed using any web browser from anywhere, at any time.

- HTML is the main markup language for web pages. It provides the basic building blocks of the interface. Everything on the screen - the colors, fonts, pictures, diagrams, tables, etc. - are created using HTML.

- JDBC is used to connect with the PostgreSQL database to perform the operation such as search, retrieve, and update information. In order to embed the JDBC code with the HTML code, Java Server Pages (JSP) syntax is necessary. Once JDBC retrieves information from the database, it can be displayed on the website using HTML. 


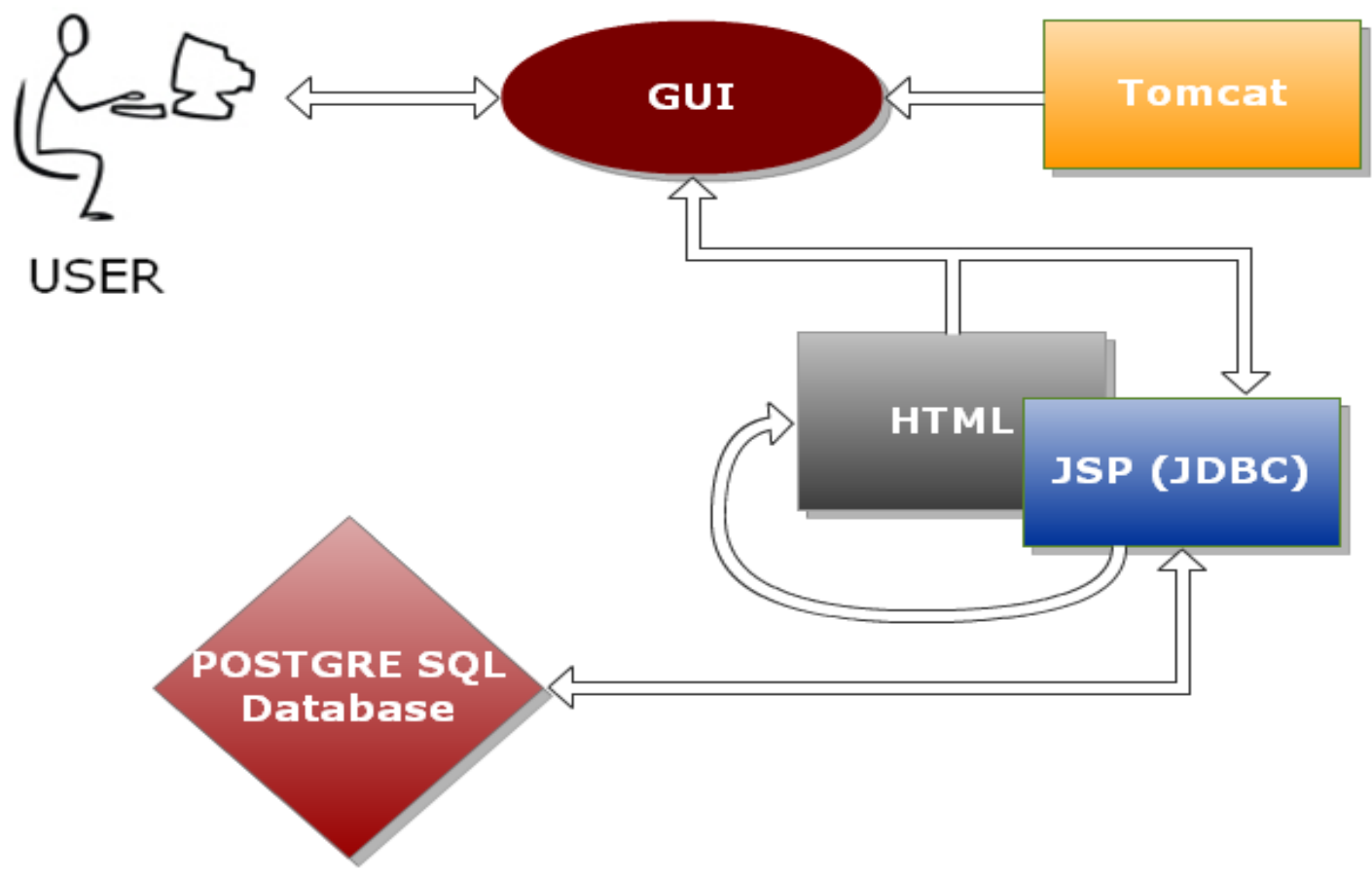

Figure 5. Web-based user interface development diagram.

\subsection{General use}

The user interface will provide input, computations, and optimization data that any user can easily retrieve. All of this information is used to determine the final decision recommendation. Figure 6 to Figure 9 are the prototype GUI screen captures of functionalities of the sustainable machining case using DGQL. As shown in the figures, functional buttons for the user to toggle are on the left hand side and the data display panel is on the right hand side. 


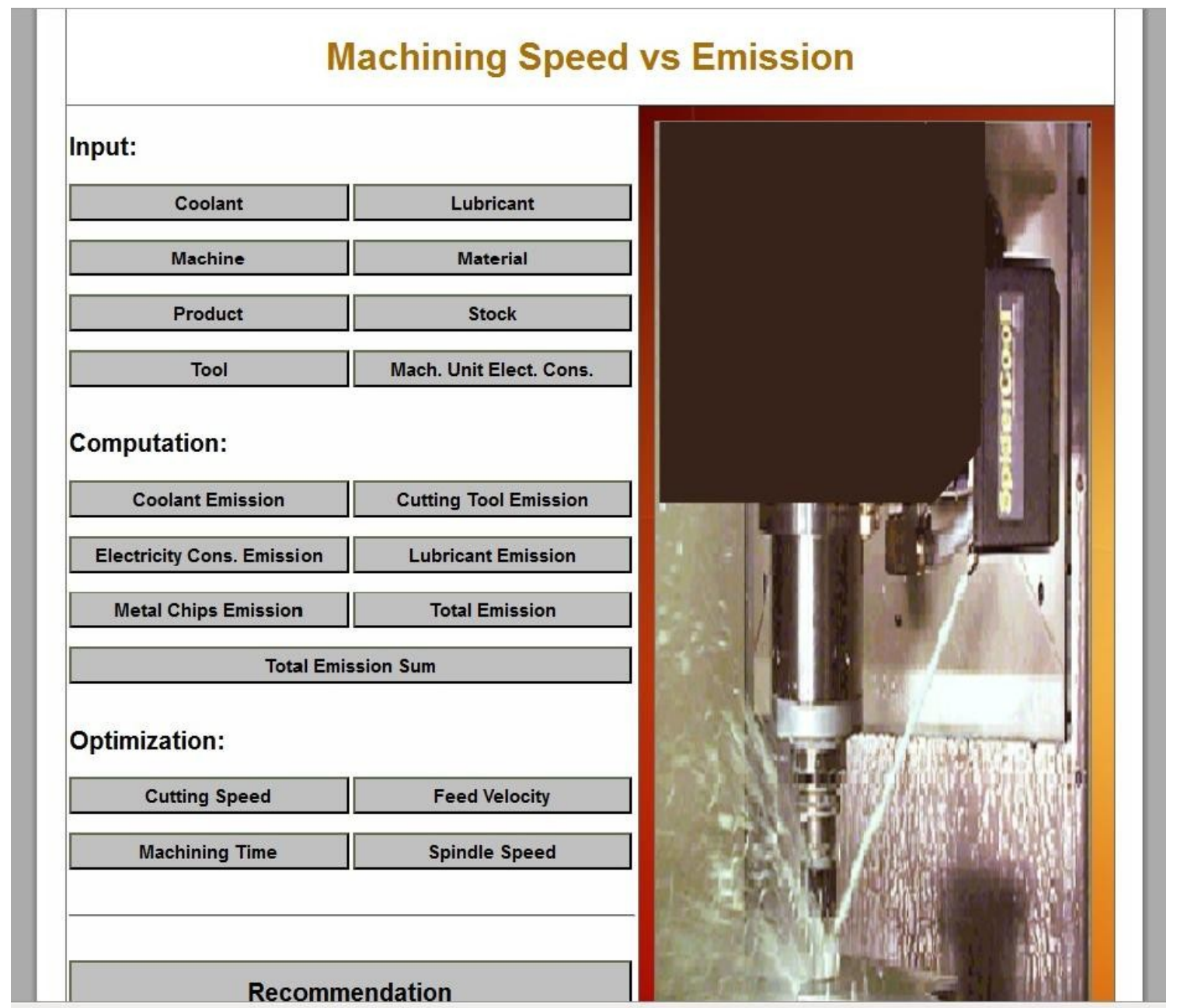

Figure 6. Main screen of web-based user interface for the sustainable machining case. 


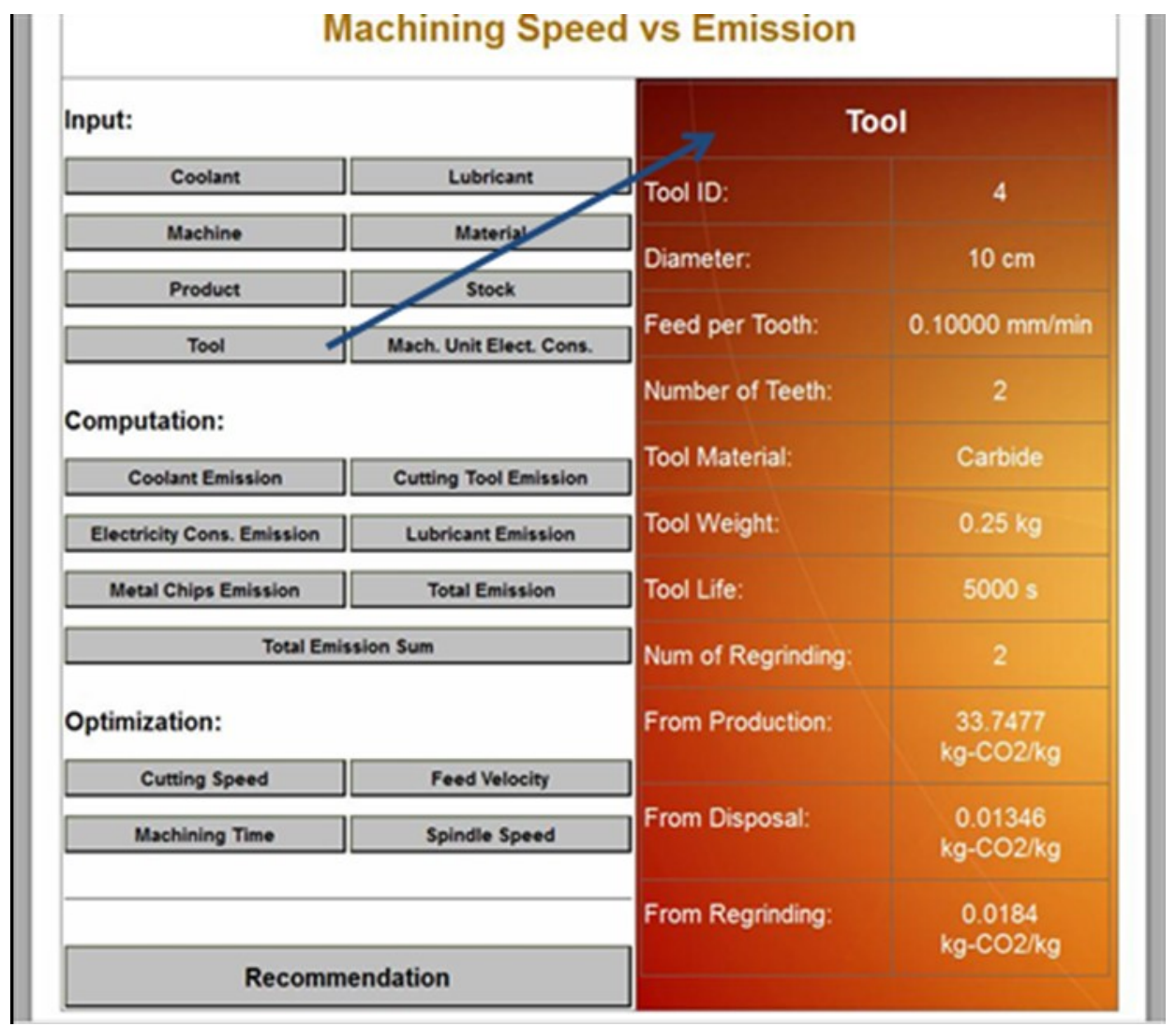

Figure 7. Input tool information screen for the sustainable machining case.

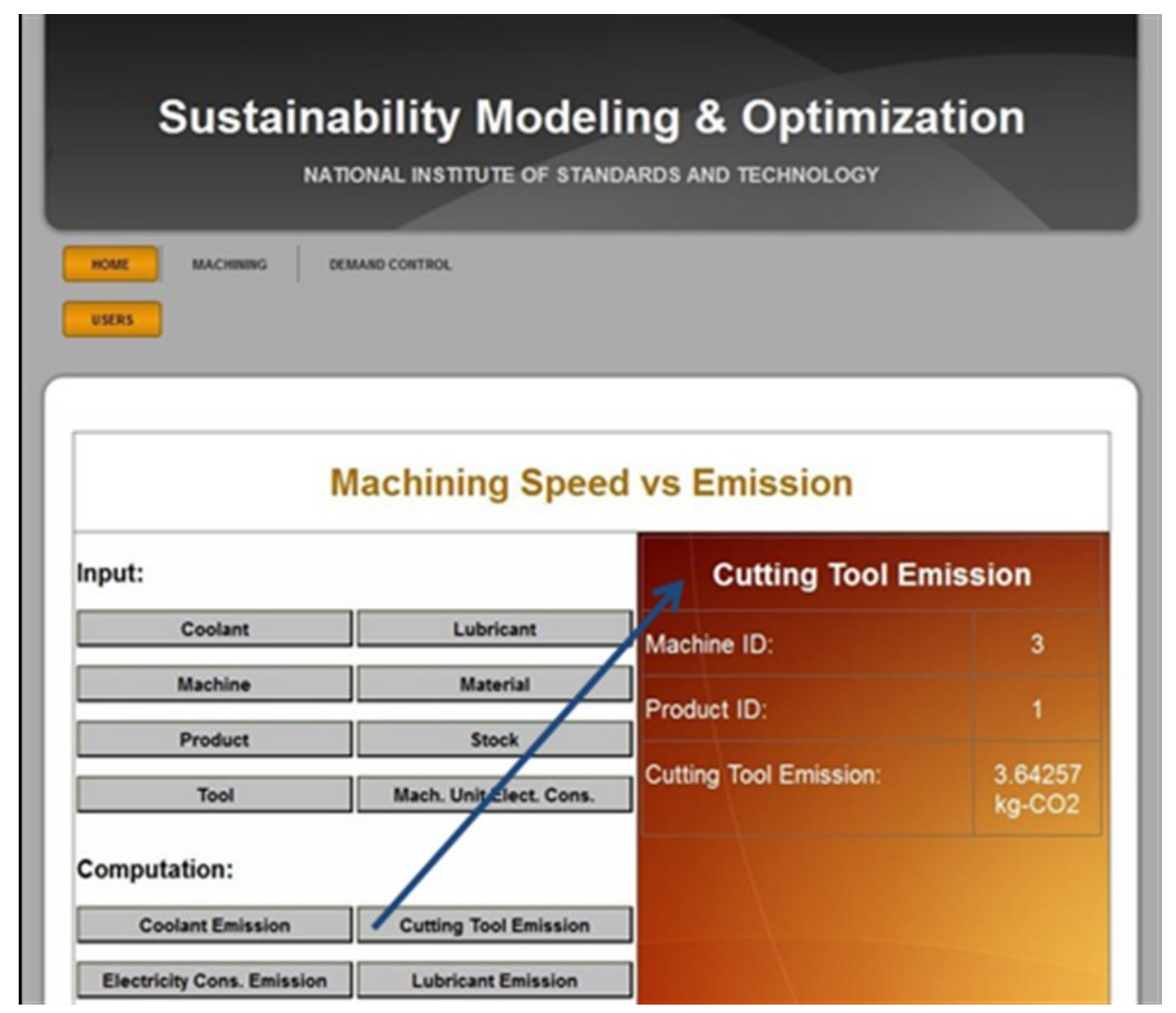

Figure 8. Computation of tool emission screen for the sustainable machining case. 


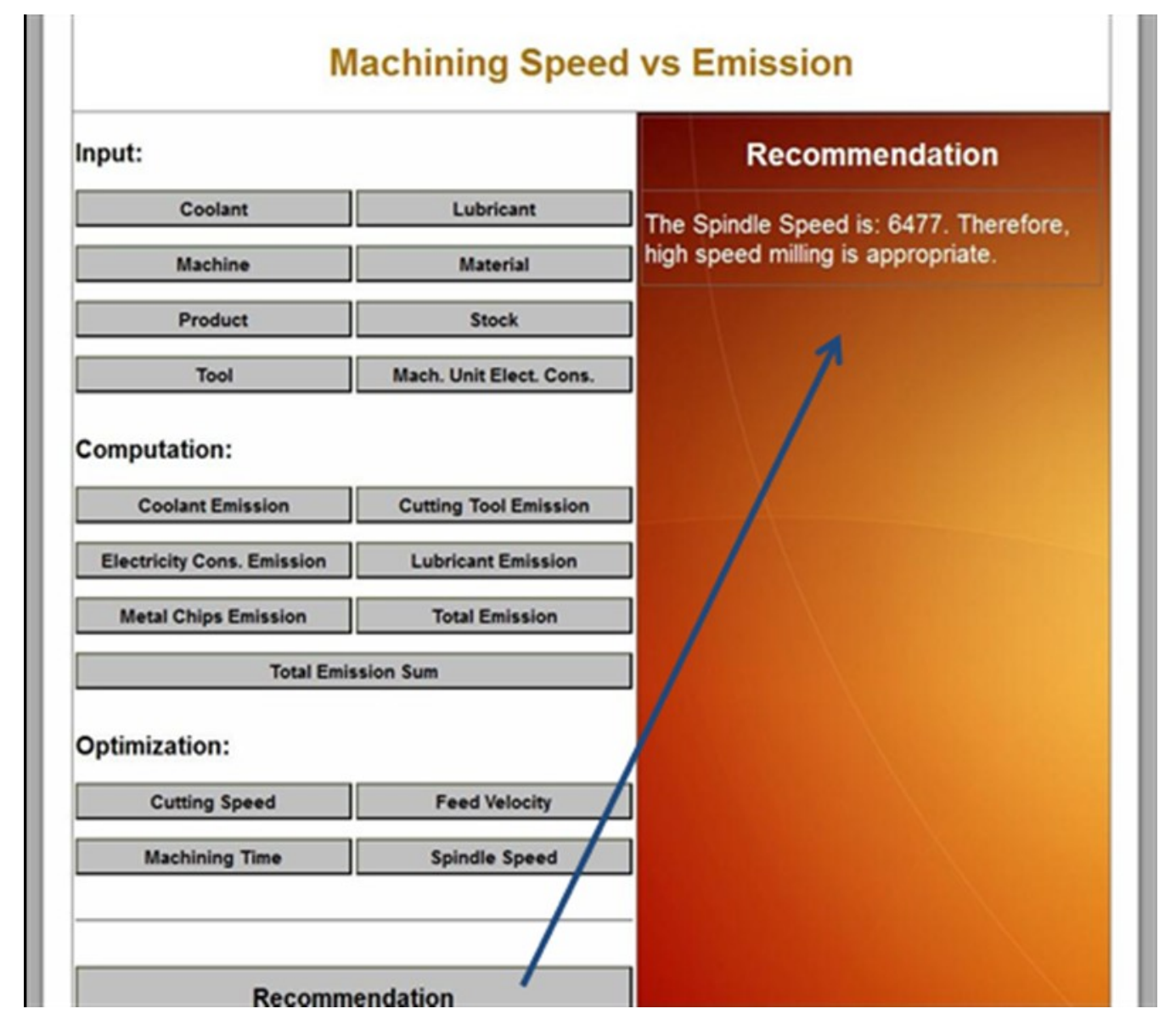

Figure 9. Recommendation of sustainable machining purchase decision.

The recommendation is displayed in Figure 9. Since the optimal Spindle Speed is $6477 \mathrm{rpm}$, the recommendation is to procure a high-speed machining center. This has shown that high-speed milling, characterized by a spindle rotation speed five to ten times faster than conventional milling, can be beneficial to sustainable manufacturing. By using DGQL modeling, we could also decide what high speed machining center needs to be purchased to minimize investment cost, with payback period or ROI as a constraint (e.g., decision maker wants to have a payback period of 2 years).

\subsection{Special purpose}

The user interface could also provide functionality for each of the four potential users - vendor, customer, decision maker, and system developer. Vendors will be able to update tables in the database. Customers will be able to look up specific product data that includes name, volume, identification, and LCA reference data associated with the products. Decision makers will be able to get an actionable recommendation or optimization results that meet their objective. System developers will be able to reconstruct any of the views, create new applications, and update, modify, or debug the system. The prototype interface screens for the four potential users are shown in Figure 10 to Figure 17.

As shown in Figure 10, specific users can navigate to their section of the site and obtain their specific functionality, assuming that they have the necessary credentials that are determined by an 
account with a username and password. Users can obtain an account by signing up.

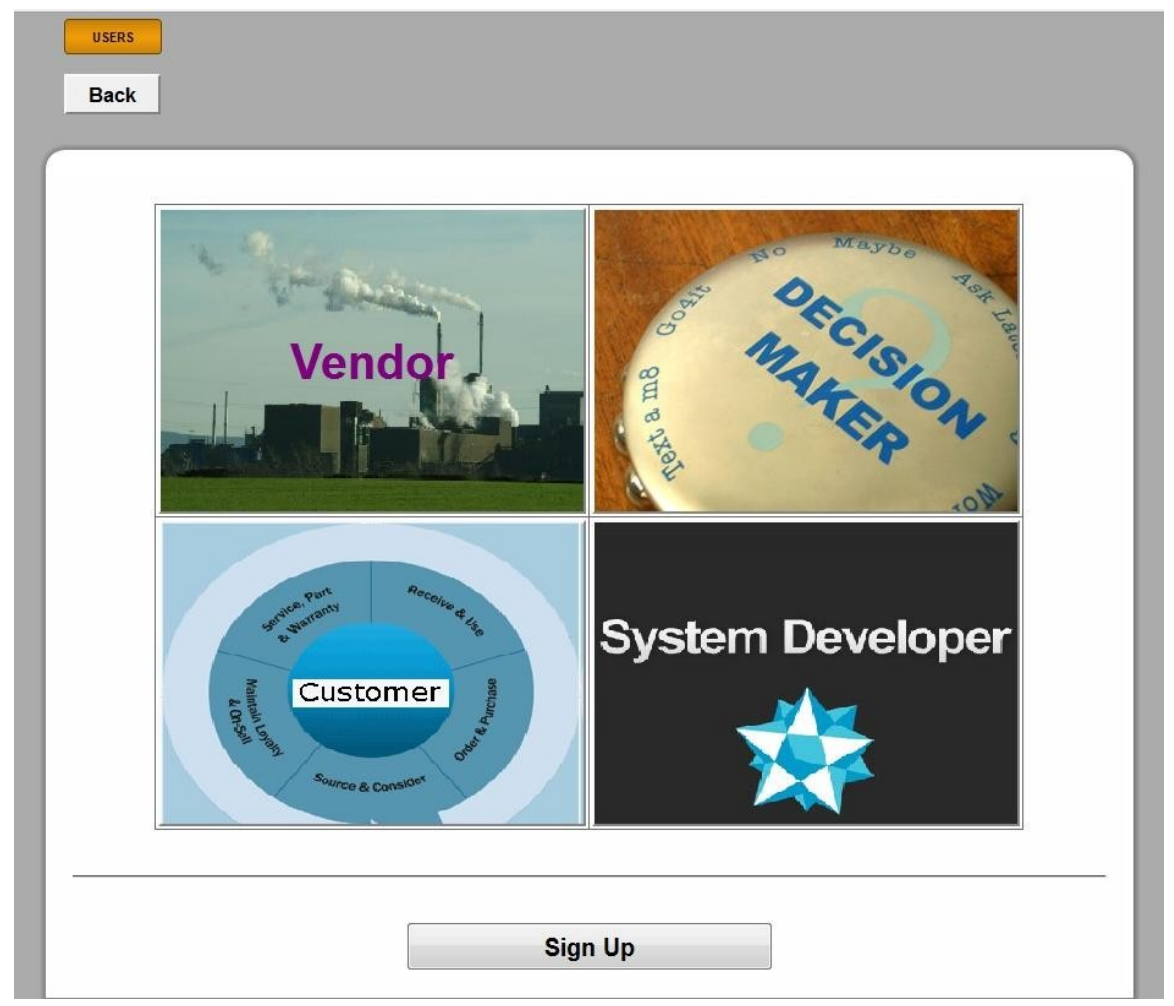

Figure 10. Initial user screen.

Figure 11 to Figure 17 provide prototype screenshots of extended functionality for each potential user of the system. For example, a vendor can choose a database to update. The two currently available are Machining and Demand Control (Figure 11). The vendor can select and update various tables for the Machining case by topic areas indicated in Figure 12. The vendor can add new coolant data including the following fields: Coolant ID, Coolant Type, Carbon Dioxide from Production, Carbon Dioxide from Disposal, and Carbon Dioxide from Water Distribution (Figure 13).

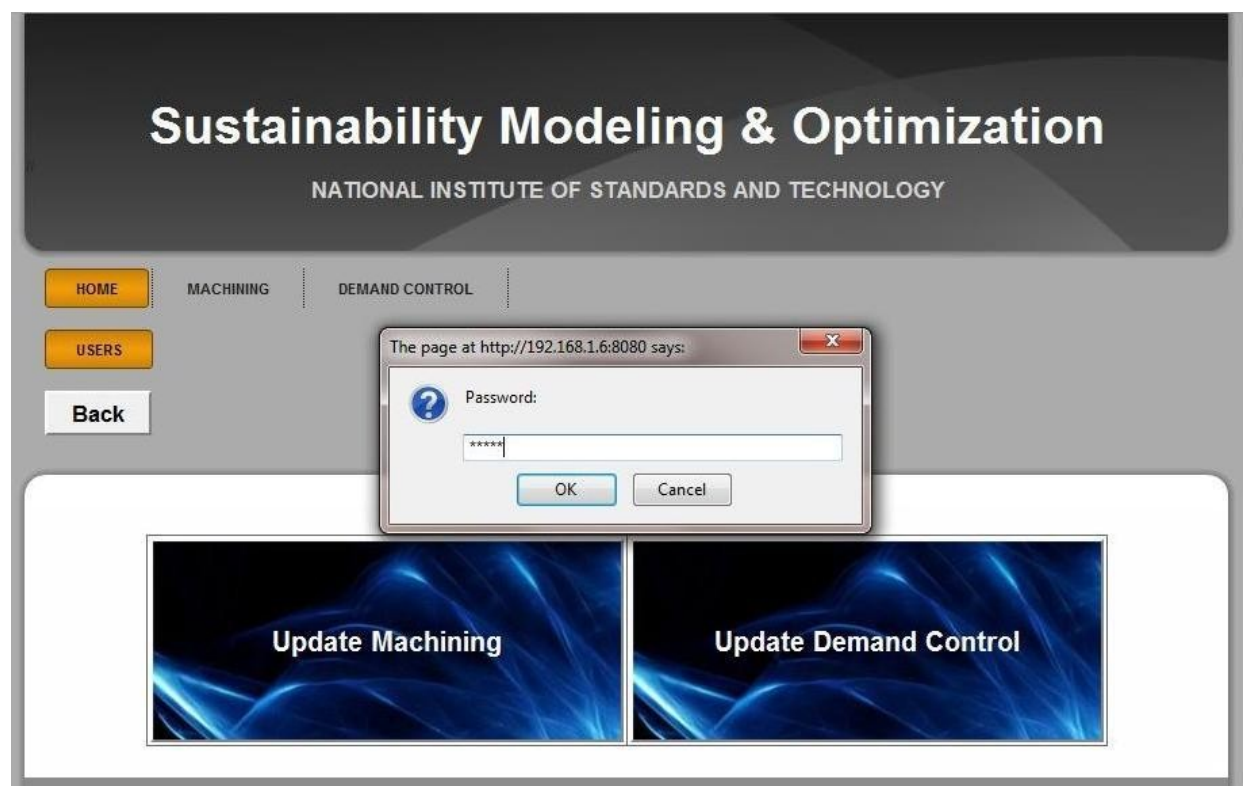


Figure 11. Vendor login interface screen.

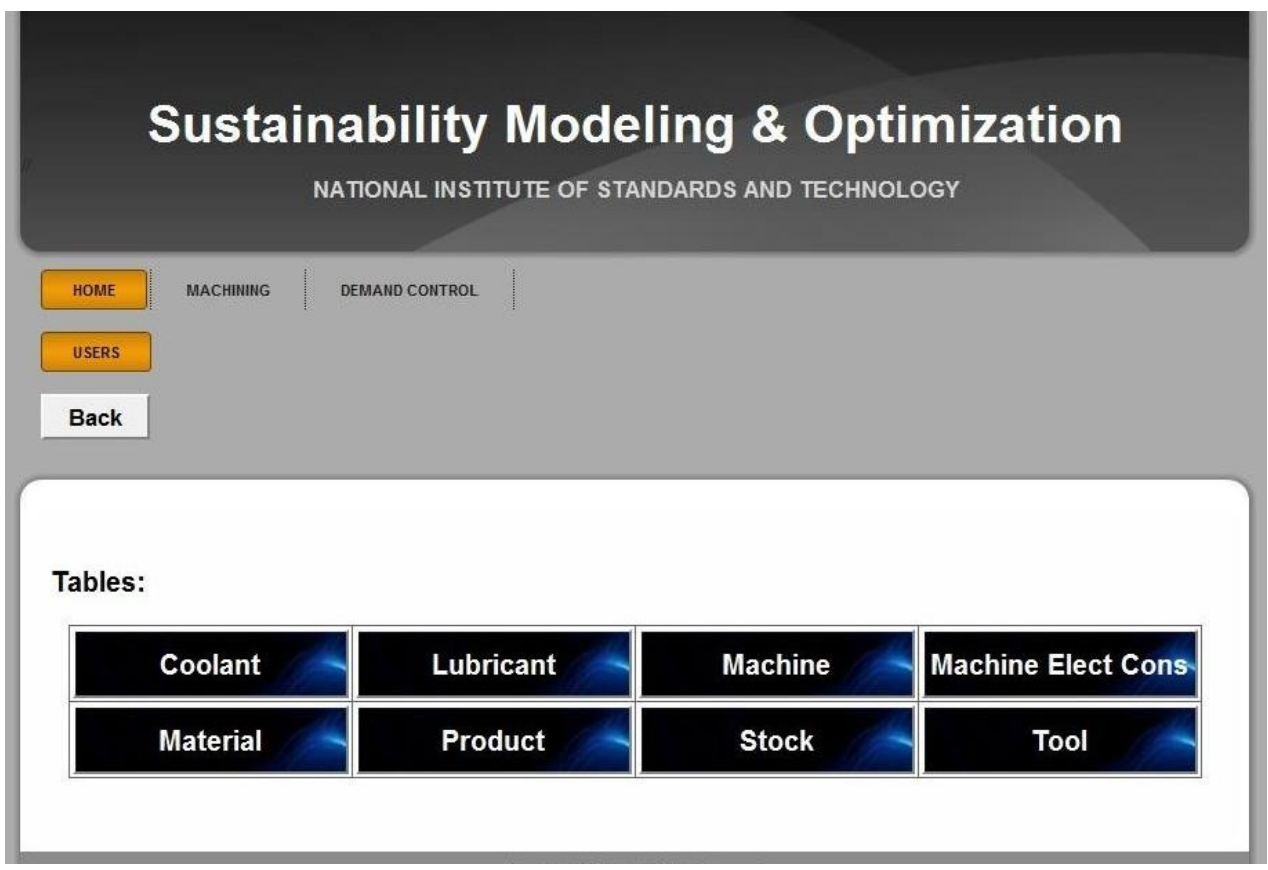

Figure 12. Screen of machining case tables for Vendor to update.

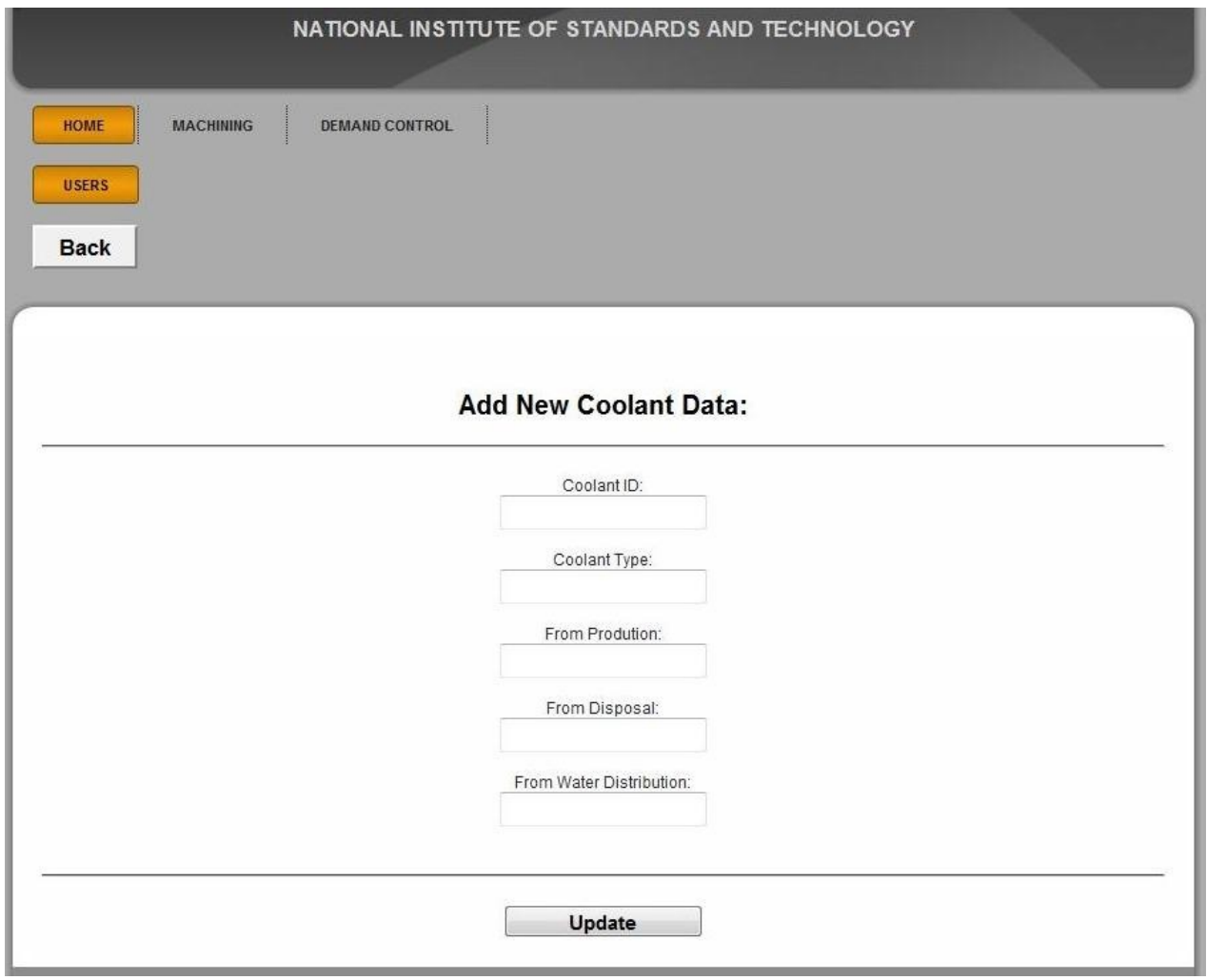

Figure 13. Screen of machining case coolant tables for Vendor to update.

A customer can view the product-related data, e.g., in Figure 14, the customer can choose to look up the product's specification or the related LCA reference data. Figure 15 shows the product view. 


\section{Sustainability Modeling \& Optimization}

NATIONAL INSTITUTE OF STANDARDS AND TECHNOLOGY

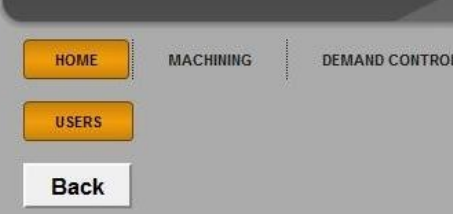

\section{Product Data}

Emissions (Environmental Impact)

Figure 14. Screen of machining case for Customer to view.

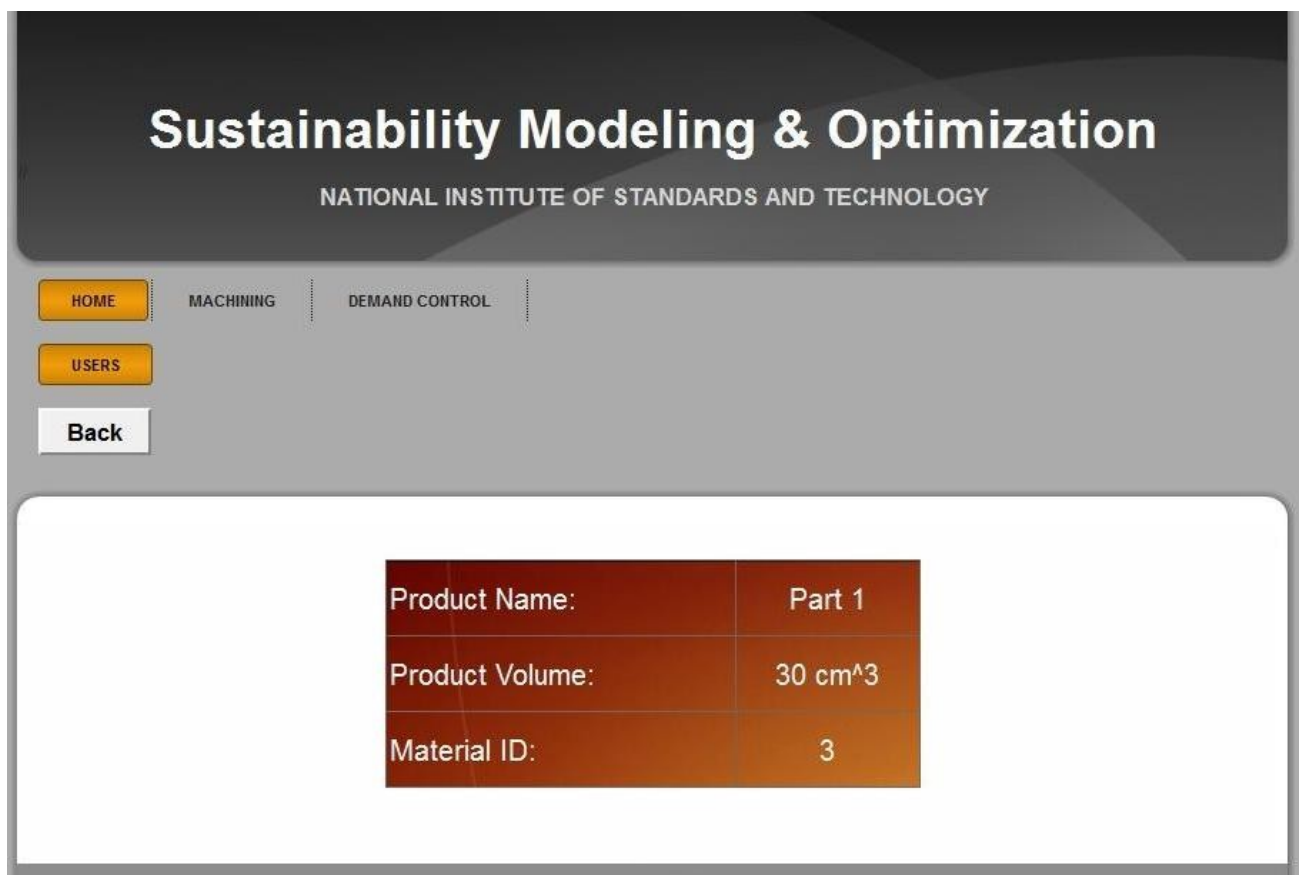

Figure 15. Screen of machining case product view for Customer.

A decision maker can view the final Recommendation. For example, the machining purchase recommendation in Figure 16 shows that a high-speed machining center is more environmental friendly. 


\section{Sustainability Modeling \& Optimization}

NATIONAL INSTITUTE OF STANDARDS AND TECHNOLOGY

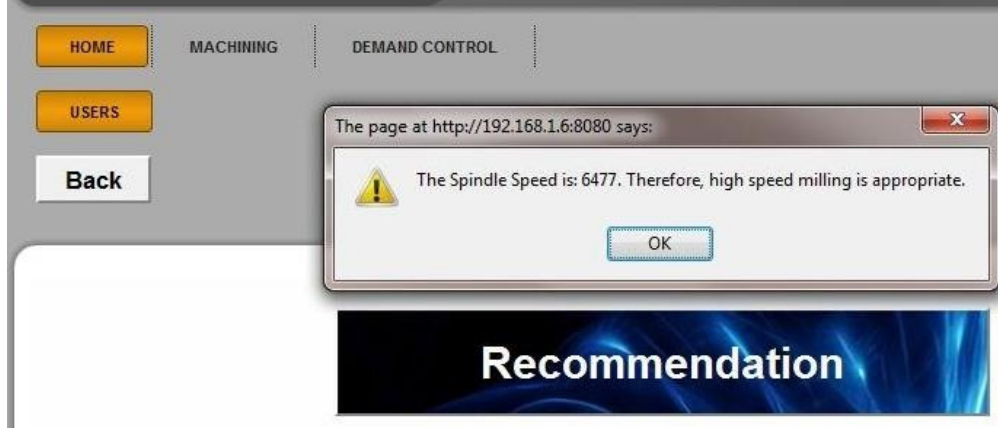

Figure 16. Screen of machining case recommendation view for Decision Maker.

A system developer can create, view, modify, and delete any machining and demand control views. S/he can also update the system data, modify the design, debug the system, and create a new application.

\section{Machining Views:

\begin{tabular}{|c|c|c|}
\hline Coolant Emission & Cutting Speed & Cutting Tool Emissio \\
\hline Feed Velocity & Lubricant Emission & Machining Time \\
\hline Spindle Speed & Total Emission & Total Emission Sum \\
\hline
\end{tabular}

Elect Cons Emission

Metal Chips Emissio

Demand Control Views:

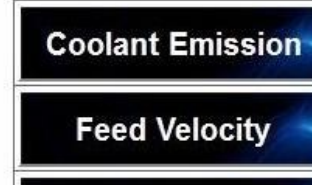

Spindle Speed

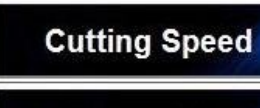

Lubricant Emission

Total Emission

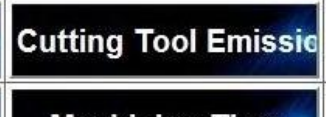

Machining Time

Total Emission Sum
Elect Cons Emission

Metal Chips Emissio

\section{Update System Data}

\section{Modify Design}

\section{Debug System}

Figure 17. Screen for System Developer. 


\section{Conclusion}

Sustainable manufacturing is gaining global attention. Modeling and optimization of the manufacturing processes, system, and strategic and investment planning successfully is very important for manufacturers to achieve their sustainable manufacturing goals. To communicate to the system users with the optimization results and prediction of the behavior of complex systems, a web-based user interface has been developed to provide users easy access to the input data, computations, optimizations, and actionable recommendations. The specified web-based user interface can be easily extended and used for more manufacturing processes in the future.

The web-based user interface was designed for the two sustainable manufacturing optimization case studies: Sustainable machining and Energy-efficient manufacturing (Demand Control). The sustainable machining case study provides recommendations for purchasing machining centers that lead to minimum emissions, while the demand control case study suggested the number of local generators needed to control the peak demand and minimize the energy cost.

The future research includes the development of generic optimization approaches, which cover information models that represents manufacturing unit processes, manufacturing unit assembly processes, process planning, and supply chain, data models and computational models required to perform optimization. As one of the decision support and optimization tools to verify and validate the generic optimization approaches, DGQL will be used to model more complex manufacturing processes and process planning for industrial case studies. Based on the prototype and research discussed in this paper, eventually, a web-based user interface will be available to aid industrial users with decisionmaking to achieve sustainable manufacturing for selected cases.

\section{DISCLAIMER}

Certain commercial software systems are identified in this paper to facilitate understanding. Such identification does not imply that these software systems are necessarily the best available for the purpose. No approval or endorsement of any commercial product by the National Institute of Standards and Technology is intended or implied.

\section{REFERENCES}

AMPL. 2011. A Modeling Language for Mathematical Programming. $<$ http://www.ampl.com/>. [accessed Oct. 2011].

Brodsky, A., and X. S. Wang. 2008. Decision-Guidance Management System (DGMS): Seamless Integration of Data Acquisition, Leaning, Prediction, and Optimization, proceedings of the $41^{\text {st }}$ Annual Hawaii International Conference on System Sciences (HICSS 2008), 71-81. Hawaii, U.S.A.

Brodsky, A. N. Egge, and X. S. Wang. 2011. Reusing Relational Queries for Intuitive Decision Optimization, proceedings of the $44^{\text {th }}$ Annual Hawaii International Conference on System Sciences (HICSS 2011). Hawaii, U.S.A.

Choi, J. K., J. A. Stuart, K. Ramani. 2003. Decision Support Tools for Environmental Product and Process Management: Survey and Needs, Environmental Informatics Archives, Volume 1 (2003), 24-37 EIA03-004. ISEIS - International Society for Environmental Information Sciences.

CPLEX. 2010. Available via $<$ http://en.wikipedia.org/wiki/CPLEX $>$ [accessed Oct. 2010].

Dahmus, J. B. and T. G. Gutowski. 2004. An Environmental Analysis of Machining, proceedings of the 2004 ASME International Mechanical Engineering Congress and RD\&D Expo. Anaheim, California, U.S.A.

Desmira, N., H. Narita, and H. Fujimoto. 2009. A Minimization of Environmental Burden of High-Speed Milling. Service Robotics and Mechatronics. Part 19. 367-372. Springer London.

DOC. 2010. Sustainable manufacturing initiative and public-private dialogue. Available via $\leq$ http://www.trade.gov/competitiveness/sustainablemanufacturing/index.asp> [accessed Oct. 2010]. 
EPA LCA. 2010. Life-Cycle Assessment (LCA). Available via < http://www.epa.gov/nrmrl/lcaccess/> [accessed March 2012].

Feng, S. C., C. B. Joung, and G, Li. 2010. Development Overview of Sustainable Manufacturing Metrics, proceedings of the 17th CIRP International Conference on Life Cycle Engineering.

Fourer, R., D. Gay, and B. W. Kernighan. 2002. A Modeling Language for Mathematical Programming. Duxbury Press; 2 edition (November 12, 2002).

Fujitsu. 2011. Fujitsu Offers Energy-Saving Green Infrastructure Solution. Available via $<$ http://www.fujitsu.com/global/news/pr/archives/month/2007/20071210-02.html > [accessed March 2012].

GAMS. 2012. The General Algebraic Modeling System (GAMS). < http://www.gams.com/> [accessed Jan. 2012].

GM. 2010. Innovation: Environment. $<$ http://www.gm.com/corporate/responsibility/environment/facilities/index.jsp $>$ [accessed March 2012].

Mort, T. 2010. Sustainability Projects. Available via <http://www.airbestpractices.com/sustainability-projects $>$ [accessed March 2012].

National Association of Manufacturers (NAM). 2010. Available via <http://www.nam.org $>$ [accessed March 2012].

NIST Workshop on Sustainable Manufacturing: Metrics, Standards, and Infrastructure: 2010. Available via $<$ http://www.mel.nist.gov/msid/conferences/Agenda_SMW.htm > [access March 2012].

PostgreSQL. 2010. About PostgreSQL. Available via $\leq \mathrm{http}: / / \mathrm{www}$. postgresql.org/about/ $\geq$ [accessed March 2012].

Rockwell Automation. 2010. Taking Energy Management to a Higher Level. Available via < http://www.managingautomation.com/maonline/research/download/view/Taking_Energy_Management_ to_a_Higher_Level_27756351>. [accessed March 2012].

SAIC. 2011. Energy Metering, Monitoring, and Control Systems. Available via $<$ http://www.saic.com/energy/efficiency/meter-monitor-control.html $>$ [access March 2012]

Seliger, G., M. K. Khraisheh, and I.S. Jawahir (eds.). 2011. Advances in Sustainable Manufacturing. Proceedings of the $8^{\text {th }}$ Global Conference on Sustainable Manufacturing. Soringer-verlag, Berlin Herdelberg.

Shao, G., A. Brodsky, J. Arinez, D. Menasce, and P. Ammann. 2011a. A Decision-Guided Energy Management for Sustainable Manufacturing, proceedings of the ASME 2011 International Design Engineering Technical Conference \&Computers and Information in Engineering Conference.

Shao, G, D. Kibira, A. Brodsky, and N. Egge. 2011b. "Decision Support for Sustainable Manufacturing using Decision Guidance Query Language.” The International Journal of Sustainable Engineering. Volume 4, Issue 3, 2011, pages 251-265.

U.S. Council for Energy-Efficient Manufacturing (USCEEM). 2011. U.S. Council for Energy-Efficient Manufacturing. Available via < http://www.usceem.org/ >. [accessed Jan. 2012]. 